\title{
CULTIVO DE ALFACE EM SOLOS COM HIDROGEL UTILIZANDO IRRIGAÇÃO AUTOMATIZADA
}

Doi:http://dx.doi.org/10.1590/1809-4430-Eng.Agric.v35n5p852-862/2015

\section{HUGO T. DOS SANTOS ${ }^{1}$, DANIEL F. DE CARVALHO ${ }^{2}$, CLAUDINEI F. SOUZA $^{3}$, LEONARDO O. MEDICI ${ }^{4}$}

RESUMO: Visando à otimização do uso da água na produção de alimentos, este artigo teve como objetivo avaliar o desempenho da TDR e de um acionador automático para irrigação na produção da alface em solos com diferentes doses de um polímero hidrofílico. Em casa de vegetação, foram realizados dois ensaios em vasos de 3 litros cultivados com alface. O primeiro foi realizado na primavera de 2011, utilizando 2 texturas de solo (arenosa e argilosa) e a presença/ausência do hidrogel. O segundo ensaio foi realizado no outono de 2012, utilizando 4 doses de hidrogel $(0 ; 8 ; 16$ e 24 g por vaso) no solo de textura arenosa. Aos 38 (2011) e 44 (2012) dias após o transplantio (DAT) das mudas, foram realizadas as colheitas e a avaliação das plantas cultivadas. O hidrogel não representou uma fonte de erros para o funcionamento da TDR, e o dispositivo acionador automático para irrigação respondeu adequadamente à presença do hidrogel nos solos com diferentes texturas. Em geral, foi verificada maior eficiência do uso da água nas plantas desenvolvidas na presença do hidrogel. As plantas cultivadas em solo com $16 \mathrm{~g}$ por vaso de hidrogel destacaram-se em massa seca e fresca da parte aérea.

PALAVRAS-CHAVE: polímero hidrofílico, TDR, automação e gotejamento.

\section{LETTUCE GROWING UNDER AUTOMATED IRRIGATION AND HYDROGEL APPLICATION}

\begin{abstract}
This paper aimed at evaluating the performance of a time domain reflectometry (TDR) and automation of an irrigation system to optimize water use in lettuce production in soils with different doses of hydrogel. For that, two greenhouse experiments were carried out with lettuce seedlings in 3-L pots. The first experiment was performed during the spring of 2011 using two soil textures (sandy and clayey) and presence or absence of hydrogel. The second one was made in the fall of 2012 using four doses of hydrogel $(0,8,16$ and $24 \mathrm{~g}$ per pot) in a sandy textured soil. The evaluations were carried out at 38 (2011) and 44 (2012) days after transplanting (DAT) of the seedlings. Results showed that hydrogel application did not affect the TDR performance. In addition, the automatic trigger device used for irrigation had adequate resposnses to hydrogel application in both soils. Overall, plants grew better in soils treated with hydrogel and the application of $16 \mathrm{~g}$ hydrogel per pot stood out since provided larger amounts of fresh and dry matter of plant shoot.
\end{abstract}

KEYWORDS: Hydrophilic polymer, TDR, Automation and Drip irrigation.

\footnotetext{
${ }^{1}$ Eng. Agrônomo, Mestrando em Eng. Sistemas Agrícolas, ESALQ, Piracicaba - SP, Fone: (19) 3447-8579 R.26, hthaner@gmail.com

${ }_{2}^{2}$ Eng. Agrícola, Prof. Doutor, Departamento de Engenharia, Instituto de Tecnologia, UFRRJ, Seropédica - RJ, carvalho@ufrrj.br

${ }^{3}$ Eng. Agrônomo, Prof. Doutor, Departamento de Recursos Naturais e Proteção Ambiental, Centro de Ciências Agrárias, UFSCAR, Araras - SP, cfsouza@cca.ufscar.br

${ }^{4}$ Eng. Agrônomo, Prof. Doutor, Departamento de Ciências Fisiológicas, Instituto de Ciências Biológicas e da Saúde, UFRRJ, Seropédica-RJ, lmedici@gmail.com

Recebido pelo Conselho Editorial em: 6-5-2013
}

Aprovado pelo Conselho Editorial em: 7-2-2015 


\section{INTRODUÇÃO}

Ao mesmo tempo em que importantes mudanças ambientais são observadas em diferentes regiões do planeta, a demanda por alimentos tem crescido, exercendo forte pressão sobre o uso da água na irrigação. A agricultura irrigada é a atividade econômica que demanda maior quantidade de água, e diversas ferramentas tecnológicas têm sido utilizadas visando a otimizar seu uso. Dentre elas, destacam-se os dispositivos automáticos de acionamento dos sistemas de irrigação, que visam a evitar aplicações excessivas de água, e o uso de substâncias hidrofílicas (HENDERSON \& HENSLEY, 1986), que contribuem para o aumento da capacidade de retenção de água no solo (CRA).

Apesar de a atividade agrícola ser dependente de inúmeros fatores do sistema solo-água-planta-atmosfera, um adequado manejo da irrigação pode ser estabelecido com base no monitoramento da umidade do solo. Para isso, diferentes técnicas têm sido utilizadas, destacando-se a Reflectometria no Domínio do Tempo (TDR) (PEREIRA et al., 2006), que apesar de exigir calibração prévia para cada tipo de solo, apresenta como vantagens a precisão e a rapidez das leituras, a não utilização de radiação ionizante, a possibilidade de automação e acoplamento a dispositivos multiplexadores de leituras, a pouca influência da textura do solo, dentre outras (SOUZA \& FOLEGATTI, 2011). O uso da TDR e de sensores ou acionadores para indicar o momento propício de irrigação tem-se mostrado viável e de alta praticidade (CARVALHO et al., 2011).

Um sistema de irrigação automatizado, quando bem programado, apresenta vantagens em relação aos sistemas tradicionais, pois evitam aplicações de lâminas excessivas e o custo de se dispor de operadores para essa função. ROMERO et al. (2012) relatam que as técnicas de controle automático para irrigação podem melhorar o uso eficiente dos recursos hídricos, mas necessitam ainda ser adotadas pelos fabricantes de equipamentos e pelos agricultores. MEDICI et al. (2010) estudaram o desempenho de um acionador simplificado para irrigação em substratos orgânico e comercial, avaliando sua eficiência na automação da irrigação. De fácil construção e de baixo custo, os autores verificaram a possibilidade de se trabalhar com tensão da água no solo dentro da faixa de -1 a $-8 \mathrm{kPa}$, obtida com a variação do desnível de um pressostato em relação a uma cápsula cerâmica inserida no solo. O mesmo acionador foi utilizado no manejo da irrigação da alface, proporcionando resultados satisfatórios sob diferentes condições de operação em campo e em casa de vegetação (BATISTA et al., 2013).

Associadas a um manejo adequado de irrigação, práticas de cultivo que promovam o aumento da CRA podem influenciar na qualidade da produção (HENDERSON et al., 1991). Nesse sentido, o uso de condicionadores de solo, conhecidos como hidrogel, tem apresentado resultados satisfatórios, principalmente em cultivo protegido, onde o uso da irrigação é imprescindível. O hidrogel é um polímero hidrofílico com a capacidade de armazenar grande quantidade de água (COELHO et al., 2008), permitindo sua liberação, em um fluxo contínuo, na quantidade necessária ao desenvolvimento das plantas (REHMAN et al., 2011).

O fornecimento de água às plantas no momento adequado e na quantidade necessária é o objetivo principal da agricultura irrigada, principalmente no cultivo de hortaliças em ambiente protegido, onde variações no conteúdo de água no solo podem afetar o desenvolvimento vegetativo, acarretando diminuição da qualidade e da produtividade das plantas (SALA \& COSTA, 2012). Considerada a hortaliça mais consumida no Brasil e uma das principais a nível mundial, a alface apresenta crescimento rápido e é muito exigente quanto às condições climáticas e à disponibilidade de água e nutrientes para que ocorra um acelerado acúmulo de massa.

Apesar de estar sendo utilizado como foco de pesquisa em diversos trabalhos na agricultura, principalmente em plantas ornamentais, condimentares e frutíferas (ALBUQUERQUE FILHO et al., 2009), não são encontrados na literatura estudos a respeito do uso do hidrogel associado a técnicas de monitoramento de umidade do solo e a dispositivos acionadores de irrigação. Assim, desenvolveu-se este trabalho com o objetivo de avaliar o cultivo de alface em solos com diferentes doses de hidrogel, utilizando a irrigação automatizada. 


\section{MATERIAL E MÉTODOS}

O experimento foi realizado em uma casa de vegetação localizada no SIPA (Sistema Integrado de Produção Agroecológica), em Seropédica-RJ (latitude 2248'00'S; longitude $43^{\circ} 41^{\prime} 00^{\prime}$ 'W; altitude de 33 metros). O abastecimento de água ao local do experimento foi feito por gravidade, e a irrigação foi controlada pelo acionador automático proposto por MEDICI et al. (2010). O dispositivo funciona em resposta à variação de tensão da água no solo próxima a uma cápsula, que é transmitida a um pressostato por meio de um tubo flexível que se encontra cheio de água. $\mathrm{O}$ desnível do pressostato em relação à cápsula cerâmica define a tensão na qual o diafragma será acionado. Uma vez atingida essa tensão, o diafragma aciona um comutador, estabelecendo a passagem de corrente elétrica, permitindo a abertura da válvula solenoide e o fornecimento de água ao sistema de irrigação.

O primeiro experimento foi realizado em 2011 (06-11 a 14-12) utilizando 16 vasos com capacidade de 3 L. O delineamento experimental adotado foi o inteiramente casualizado (DIC), em fatorial $2 \times 2$, com quatro repetições, sendo o fatorial caracterizado pela ausência/presença de hidrogel (5 $\left.\mathrm{g} \mathrm{vaso}^{-1}\right)$ e 2 texturas de solo (argilosa e arenosa). Foi adotado um desnível de pressostato de $0,9 \mathrm{~m}$.

Quando o hidrogel tinha sua hidratação reduzida e o solo encontrava-se com baixa umidade, o dispositivo automático acionava a irrigação que era concluída quando o hidrogel e/ou o solo apresentavam o teor de hidratação/umidade em equilíbrio com a cápsula cerâmica (MEDICI et al., 2010).

As amostras de solo foram obtidas em uma área localizada no Câmpus da UFRRJ, sendo coletadas do horizonte B textural $\left(\mathrm{B}_{\mathrm{t}}\right)$ de um Argissolo Vermelho-Amarelo distrófico abrúptico e do horizonte superficial (A moderado) de um Planossolo Háplico distrófico arênico, caracterizando, dessa forma, as duas texturas de solo. As amostras foram submetidas à secagem ao ar livre e, em seguida, destorroadas em peneira mecânica com crivo de $0,002 \mathrm{~m}$. A Tabela 1 apresenta o resultado das análises físicas dos solos utilizados nos ensaios (EMBRAPA, 2011).

TABELA 1. Características físicas dos solos utilizados nos ensaios. Soil physical characteristics.

\begin{tabular}{|c|c|c|c|c|c|c|c|}
\hline \multirow{3}{*}{ Amostra } & \multirow{3}{*}{$\begin{array}{l}\text { Profundidade } \\
\qquad(\mathrm{cm})\end{array}$} & \multirow{2}{*}{ Argila } & \multicolumn{3}{|c|}{ Areia } & \multirow{2}{*}{ Silte } & \multirow{2}{*}{ Ds } \\
\hline & & & Total & fina & Grossa & & \\
\hline & & & & $\mathrm{g} \mathrm{kg}^{-1}$ & & & $\mathrm{~g} \mathrm{~cm}^{-3}$ \\
\hline Planossolo & $0-20$ & 60 & 830 & 220 & 610 & 110 & 1,25 \\
\hline Argissolo & $50-100$ & 170 & 690 & 200 & 490 & 140 & 1,38 \\
\hline
\end{tabular}

O segundo ensaio foi realizado em 2012 (24/05 a 06/07), utilizando o delineamento experimental de blocos casualizados (DBC), com quatro tratamentos (doses de hidrogel) e seis repetições, totalizando 24 parcelas. Adotando o mesmo desnível do pressostato $(0,9 \mathrm{~m})$ e o volume de vaso (3 L), utilizou-se apenas do solo de textura arenosa (Planossolo Háplico distrófico arênico), sendo os tratamentos caracterizados por $0 ; 8 ; 16$ e $24 \mathrm{~g}$ de hidrogel por vaso.

Nos dois ensaios, as mudas de alface (cv Regina) foram produzidas em substrato orgânico constituído por vermicomposto, carvão vegetal triturado e torta de mamona (SILVA et al., 2009). As sementes foram dispostas em bandeja de poliestireno expandido, dentro da mesma casa de vegetação, permanecendo 30 dias até o transplantio para os vasos (BEZERRA NETO et al., 2011). Utilizou-se do hidrogel da marca comercial Stockosorb $500^{1}$, o qual foi incorporado manualmente às amostras de solo nos vasos do transplante das mudas.

Foi instalado um acionador automático para cada vaso, estando as válvulas solenoides acopladas em uma tubulação de PVC com diâmetro de 3/4"' (linha de derivação), que conectavam as

\footnotetext{
${ }^{1}$ Referências à marca registrada não constituem endosso por parte dos autores.
} 
mangueiras de polietileno de $1 / 2$ " (linha lateral), onde estavam instalados os gotejadores (modelo Katiff - John Deere Water ${ }^{1}$ ), com vazão nominal de $2,8 \mathrm{~L} \mathrm{~h}^{-1}$. No final de cada linha lateral, foi instalado um recipiente visando ao monitoramento diário do volume de água aplicado nos vasos. Os acionadores foram instalados em paralelo, permitindo a irrigação independente para cada tratamento. A cápsula cerâmica do dispositivo foi instalada a $0,15 \mathrm{~m}$ de profundidade, nos vasos que receberam inicialmente um volume de água de aproximadamente $150 \mathrm{~mL}$, a fim de uniformizar a umidade do solo e facilitar o desenvolvimento inicial das mudas.

Antes do início dos ensaios, foi realizada a calibração da TDR (CARVALHO et al., 2013), permitindo a obtenção de equações relacionando a leitura da constante dielétrica aparente (ka) com a umidade volumétrica para os solos com diferentes texturas e doses do hidrogel. Durante os ensaios, foram realizadas três leituras semanais da ka por meio de sondas com três hastes contínuas de $0,20 \mathrm{~m}$, instaladas verticalmente e abrangendo todo o volume de solo presente no vaso.

O monitoramento meteorológico no interior da casa de vegetação foi realizado por meio de um termo-higrógrafo automático com datalogger, que registrava as leituras de temperatura e umidade relativa a cada hora do dia. As condições meteorológicas externas também foram monitoradas a partir dos dados de uma estação automática, instalada próxima à casa de vegetação.

As colheitas da alface foram realizadas manualmente aos 38 e 44 dias, após o transplante das mudas (DAT). As plantas colhidas foram embaladas em sacos plásticos, para a análise das variáveis de produção: massa fresca (MFC), massa seca (MSC), diâmetro (DI), altura (AL), número de folhas (NF) da parte aérea, área foliar (AF) e massa fresca da raiz (MFR) (FOLTRAN \& TEIXEIRA, 2004; MORAES et al., 2001). A eficiência do uso da água (EUA) na produção da alface foi também avaliada nos dois ensaios pela razão entre a MSC e a MFC com o volume de água aplicado em cada tratamento.

A massa fresca e a seca de cada parte da planta foram determinadas em uma balança analítica (mod. Adventurer OHAUS ${ }^{1}$ ). A AF $\left(\mathrm{cm}^{2}\right)$ foi determinada em aparelho medidor modelo LI-3100C Area Meter (LICOR ${ }^{1}$, USA). O DI e AL foram mensurados em uma fita métrica com precisão igual a 0,005 m. Após as mensurações, cada material foi embalado em sacos de papel identificados e conduzido à estufa de ventilação forçada, a $65^{\circ} \mathrm{C}$, por 48 horas.

Foi realizada a análise de variância (ANOVA) no experimento de 2011 e, quando ocorreu interação significativa, aplicou-se o Teste F de Snedecor no desdobramento dos graus de liberdade. Os resultados obtidos no experimento com as das diferentes doses de hidrogel foram submetidos à ANOVA com testes para as regressões lineares e quadráticas (KAPS \& LAMBERSON, 2004).

\section{RESULTADOS E DISCUSSÃO}

Durante a realização dos ensaios, a temperatura mínima e a umidade relativa média da casa de vegetação enquadraram-se dentro dos limites recomendados ao desenvolvimento da alface que segundo LIMA JÚNIOR et al. (2010), são de, respectivamente, 6 a $30{ }^{\circ} \mathrm{C}$ e 60 a $80 \%$. Por outro lado, alguns valores de temperatura máxima registrados no interior da casa de vegetação no ano de 2011, encontraram-se acima do limite de temperatura requerido pela cultura, visto que o experimento foi conduzido no final da estação da primavera. Nesse ano, a cultura completou seu ciclo 12 dias antes do programado, aos 38 DAT. O experimento realizado em 2012 foi conduzido no outono, e as temperaturas máximas registradas apresentaram-se dentro da faixa térmica favorável ao desenvolvimento da alface, que foi colhida aos 44 DAT.

Para o experimento realizado em 2011, o resultado da ANOVA identificou que os solos com hidrogel apresentaram diferenças significativas para a variável volume de água e, pelo teste $\mathrm{F}$, verificou-se que ambos os solos com hidrogel receberam menores volumes de água pelo dispositivo acionador. As plantas cultivadas na presença do hidrogel receberam, em média, 2,76 L de água, enquanto aquelas cultivadas sem o hidrogel receberam 3,3 L de água.

O dispositivo automático aplicou menores volumes de água na presença do hidrogel, pois estas têm maior capacidade de hidratação que as partículas do solo (HENDERSON \& HENSLEY, 
1986), e quando hidratadas podem ter atuado como uma barreira estrutural para minimizar a evaporação da água no solo (BAKASS et al., 2002; AKHTER et al., 2004). Dessa forma, a presença do hidrogel manteve o solo com maior conteúdo de água e, possivelmente, a cápsula cerâmica do acionador recebeu os efeitos da hidratação do polímero, fazendo com que o acionamento da irrigação fosse menos frequente. $\mathrm{O}$ aumento na CRA proporcionado pela presença do hidrogel também contribuiu para menores volumes de água aplicados em 2011; o Planossolo, por exemplo, recebeu 2,81 L de água com hidrogel e 3,44 L na ausência do polímero.

O volume de água utilizado na cultura da alface, em 2012, foi menor que em 2011, sendo a dosagem de hidrogel de $8 \mathrm{~g}$ por vaso a que proporcionou, em média, menor volume aplicado (Figura 1).

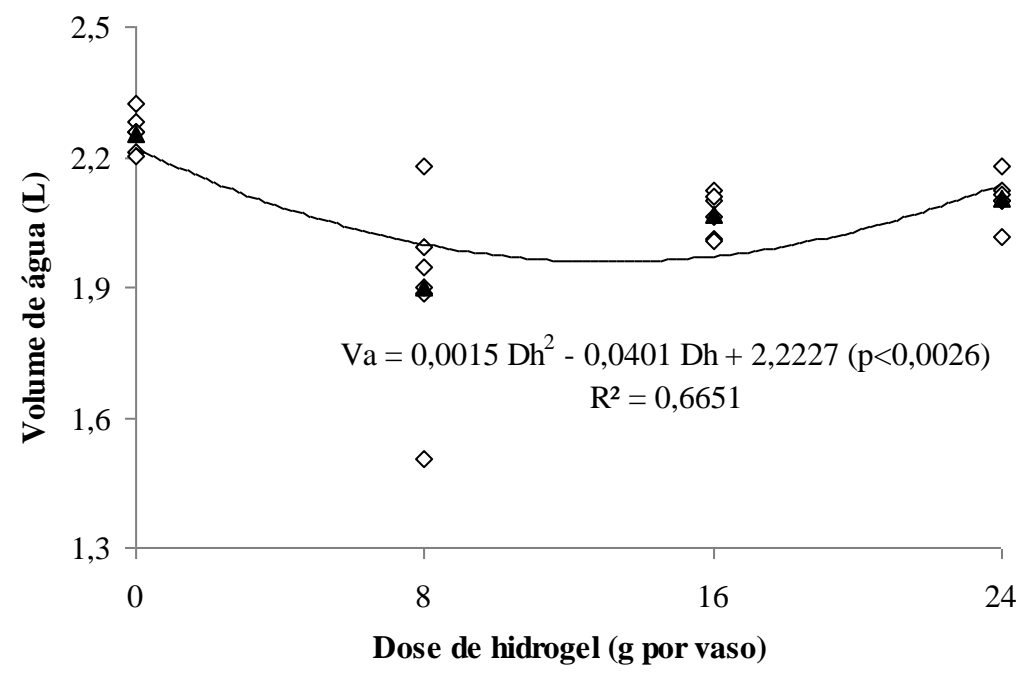

FIGURA 1. Análise de regressão para o volume de água utilizado (Va) na produção da alface no ano de 2012, em função de diferentes doses de hidrogel (Dh) em solo arenoso. Regression analysis for the volume of water (Va) used for lettuce production in 2012, under different doses of hydrogel (Dh) in a sandy soil.

O experimento realizado em 2011 foi conduzido na primavera, e as condições meteorológicas desta estação propiciaram maior demanda hídrica das plantas, uma vez que as temperaturas máximas registradas na casa de vegetação estavam próximas do limite tolerável pela cultura.

Outro fator que contribuiu para a diferença de volume de água nos ensaios foi a dosagem de hidrogel, que em 2011 correspondia a 20,8\% da maior dosagem utilizada em 2012. Esperava-se que os tratamentos com maiores doses de polímero apresentassem menores volumes médios de água aplicados. No entanto, foi observado, que após os primeiros eventos de irrigação, os tratamentos com maiores doses de hidrogel receberam as maiores quantidades de água de todo o cultivo e, consequentemente, apresentaram maiores valores de umidade volumétrica após as irrigações. Vale ressaltar que o volume de água aplicado em cada irrigação se refere à necessidade hídrica da cultura somada à quantidade de água necessária para a hidratação do polímero, fato constatado por WILLINGHAM \& COFFEY (1981), ao avaliarem o efeito de diferentes doses de hidrogel na produção de mudas de tomate. Pode-se deduzir que maior parte do volume de água aplicado foi utilizada na hidratação do polímero (ABEDI-KOUPAI et al., 2008), uma vez que a muda da alface estava recém-transplantada e os primeiros 18 dias após o transplantio não se caracterizam como a fase de maior demanda hídrica da cultura (LIMA JÚNIOR et al., 2010). Portanto, quanto maior a quantidade de hidrogel no solo, maior é a quantidade de água necessária para hidratá-lo (EKEBAFE et al., 2011), e, após hidratação, o polímero inicia a liberação lenta da água no solo (PREVEDELLO \& LOYOLA, 2007).

A Tabela 2 apresenta os coeficientes das equações de calibração da constante dielétrica aparente (ka) em função da umidade volumétrica nos solos com diferentes texturas e doses de 
hidrogel. O ajuste é considerado satisfatório e permitiu o monitoramento do conteúdo de água no solo ao longo dos ensaios.

TABELA 2. Coeficientes das equações de calibração da TDR. Coefficients of TDR calibration equations.

\begin{tabular}{cccc}
\hline Tratamentos & \multicolumn{3}{c}{$\theta\left(\mathrm{cm}^{3} \mathrm{~cm}^{-3}\right)=\mathrm{a}^{*} \mathrm{ka}+\mathrm{b}$} \\
\cline { 2 - 4 } & $\mathrm{a}$ & $\mathrm{b}$ & $\mathrm{R}^{2}$ \\
\hline & $1^{\mathbf{o}}$ ensaio $(2011)$ & 0,91 \\
Planossolo sem hidrogel & 0,0415 & $-0,0931$ & 0,90 \\
Argissolo sem hidrogel & 0,0200 & 0,2186 & 0,91 \\
Planossolo com hidrogel & 0,0252 & $-0,0039$ & 0,95 \\
Argissolo com hidrogel & 0,0330 & $-0,0548$ & 0,91 \\
\hline & $2^{\mathbf{o}}$ ensaio $(2012)$ & 0,85 \\
\hline 8 g de hidrogel por vaso & 0,0093 & 0,1320 & 0,91 \\
\hline 16 g de hidrogel por vaso & 0,0161 & 0,1190 & 0,1454 \\
24 g de hidrogel por vaso & 0,0183 & &
\end{tabular}

Em todos os tratamentos com hidrogel, foram observados maiores valores da ka quando comparados aos tratamentos sem hidrogel. A adição de hidrogel proporciona aumento da CRA e, consequentemente, aumento da quantidade de água livre no meio, refletindo nos valores de ka. Em 2011 (Figura 2a), verificou-se que o Planossolo com hidrogel apresentou altos valores de umidade volumétrica, se comparado ao sem hidrogel, sendo esta, contudo, inferior à do Argissolo com hidrogel. Vale ressaltar que os Argissolos apresentam alta CRA (LEPSCH, 2002) e ainda maior com a presença do polímero hidrofílico.

No ano de 2012, verificou-se que a TDR apresentou bom desempenho no monitoramento do conteúdo de água do solo, independentemente da dose de hidrogel utilizada (Figura 2b). Observouse que quanto maior a dose de hidrogel aplicada maior o valor da ka e, consequentemente, maior a umidade volumétrica, sendo o resultado também verificado durante o processo de calibração da TDR nas diferentes doses. O resultado encontrado corrobora IDOBRO et al. (2010), que avaliaram o comportamento de três doses de hidrogel em um solo arenoso e observaram que o tratamento de maior dose (40 g por vaso) apresentou os maiores valores de umidade volumétrica, proporcionando aumento mais expressivo em sua CRA.

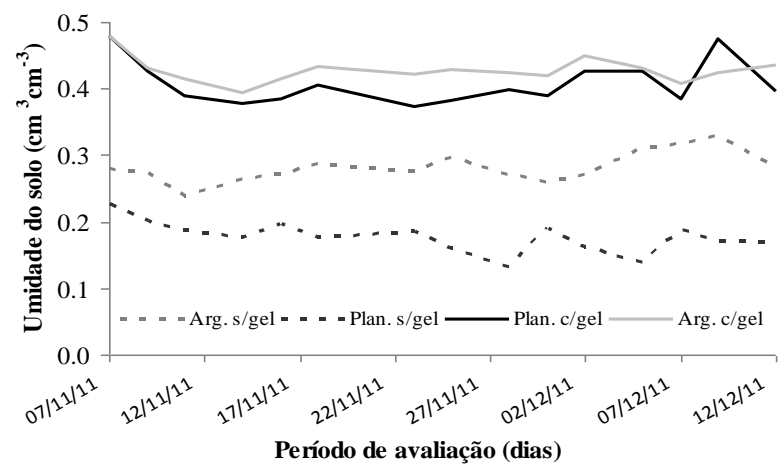

a

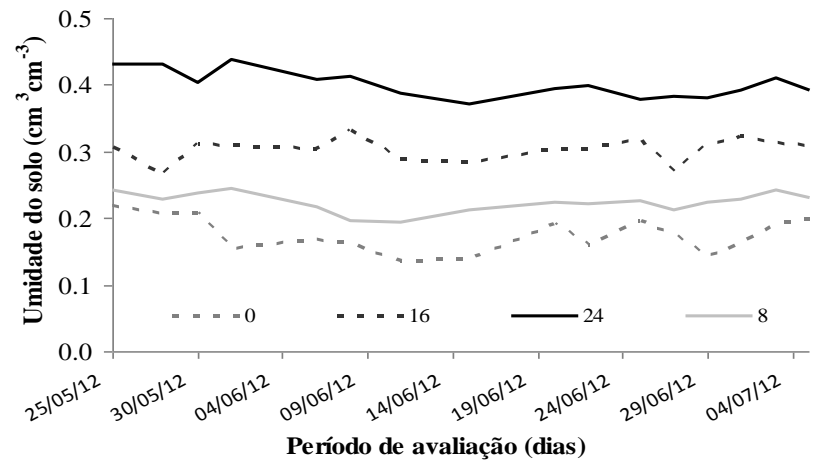

b

FIGURA 2. Variação do conteúdo de água: (a) nos solos com e sem hidrogel (2011); e (b) no solo arenoso, com diferentes dosagens de hidrogel (2012). Water content variation: (a) in soils with and without hydrogel (2011); and (b) in a sandy soil with different doses of hydrogel (2012).

No experimento conduzido em 2011, foi observado que a presença do hidrogel, em ambos os solos, não afetou significativamente a produção da alface. As maiores médias para as variáveis altura e número de folhas foram obtidas nas plantas cultivadas com a ausência do polímero 
hidrofílico (Tabela 3). LIMA et al. (2003) avaliaram os efeitos do uso do hidrogel e de diferentes lâminas de irrigação sob a produção de mudas de Coffea arabica em ambiente protegido, em Uberlândia (MG). Os autores utilizaram 3,1 g de hidrogel por planta e observaram que o polímero não afetou significativamente o número de folhas e a altura das mudas de café.

TABELA 3. Efeito do hidrogel nas variáveis de produção da alface em solos de diferentes texturas. Effect of hydrogel on lettuce production grown on soils of different textures.

\begin{tabular}{ccccccccc}
\hline \multirow{2}{*}{$\begin{array}{c}\text { Tipos de } \\
\text { solo }\end{array}$} & \multicolumn{2}{c}{ Altura $(\mathrm{cm})$} & \multicolumn{2}{c}{$\begin{array}{c}\text { Número de folhas } \\
\text { (un) }\end{array}$} & \multicolumn{2}{c}{$\begin{array}{c}\text { Massa fresca da parte } \\
\text { aérea }(\mathrm{g})\end{array}$} & $\begin{array}{c}\text { Massa seca da parte } \\
\text { aérea }(\mathrm{g})\end{array}$ \\
\cline { 2 - 9 } & com gel & sem gel & com gel & sem gel & com gel & sem gel & com gel & sem gel \\
\hline Argissolo & 23,32 & 27,52 & 36,00 & 37,50 & $153,1 \mathrm{Aa}$ & $116,55 \mathrm{Bb}$ & $6,77 \mathrm{Aa}$ & $5,55 \mathrm{Bb}$ \\
Planossolo & 24,10 & 27,45 & 32,75 & 35,75 & $135,98 \mathrm{Bb}$ & $183,66 \mathrm{Aa}$ & $6,26 \mathrm{Bb}$ & $7,56 \mathrm{Ba}$ \\
\hline
\end{tabular}

$\begin{array}{lllllllll}\text { Média } & 23,71 \mathrm{~b} & 27,48 \mathrm{a} & 34,37 \mathrm{Bb} & 36,62 \mathrm{Aa} & 144,54 & 150,11 & 6,51 & 6,55\end{array}$

Médias seguidas de letras minúsculas na linha ou letras maiúsculas na coluna diferem significativamente entre si pelo teste $\mathrm{F}$ $(\mathrm{p}<0,05)$.

Em 2011, os tratamentos com hidrogel apresentaram maiores EUA, sendo o resultado mais expressivo no solo de textura argilosa, cujas plantas apresentaram maiores MSC e MFC com menores consumos de água, se comparado com o tratamento sem hidrogel. A Tabela 4 apresenta as médias de eficiência do uso da água obtidas no ensaio de 2011.

TABELA 4. Efeito do hidrogel na EUA da alface no ano de 2011. Effect of hydrogel on lettuce water use efficiency (WUE) in 2011.

\begin{tabular}{ccccc}
\hline \multirow{2}{*}{ Tipos de solo } & \multicolumn{2}{c}{ EUA em massa seca $\left(\mathrm{g} \mathrm{L}^{-1}\right)$} & \multicolumn{2}{c}{ EUA em massa fresca $\left(\mathrm{g} \mathrm{L}^{-1}\right)$} \\
\cline { 2 - 5 } & com gel & sem gel & com gel & sem gel \\
\hline Argissolo & 2,47 & 1,76 & $55,60 \mathrm{Aa}$ & $36,85 \mathrm{Bb}$ \\
Planossolo & 2,26 & 2,20 & $48,97 \mathrm{Bb}$ & $53,54 \mathrm{Aa}$ \\
\hline Média & $2,37 \mathrm{a}$ & $1,98 \mathrm{~b}$ & 52,29 & 45,20 \\
\hline
\end{tabular}

Médias seguidas de diferentes letras minúsculas na linha ou maiúsculas na coluna diferem significativamente entre si, pelo teste $\mathrm{F}$ $(\mathrm{p}<0,05)$.

BERNARDI et al. (2005) estudaram o efeito do hidrogel sobre a produção do meloeiro (Cucumis melo) em cultivo protegido, utilizando vasos de $3 \mathrm{~L}$ com solo arenoso (Neossolo Quartzarênico). A dose ideal para o cultivo foi de $17 \mathrm{~g}$ por vaso, que possibilitou maior massa fresca de frutos. MORAES et al. (2001) verificaram o efeito da utilização do hidrogel sobre o intervalo de irrigação no cultivo da alface cv. Tainá, em solo argiloso, e constataram interação entre o efeito do hidrogel e o efeito do intervalo da irrigação para MFC e MSC, sendo as maiores médias obtidas provenientes do tratamento com maior dosagem de hidrogel (10 $\mathrm{g}$ por planta).

ZONTA et al. (2009) realizaram um experimento, em casa de vegetação em Alegre (ES), com mudas de café conillon cv. Pierre, em vasos de $10 \mathrm{~L}$ preenchidos com solo argiloso (Argissolo Vermelho-Amarelo), visando a estudar os efeitos de diferentes doses de hidrogel $(0 ; 3 ; 6$ e 9 g por vaso) na fase inicial de desenvolvimento da lavoura. A dose de $9 \mathrm{~g}$ por vaso foi a que proporcionou o melhor desenvolvimento das mudas de café conillon. A partir dos resultados do trabalho de ZONTA et al. (2009) e MORAES et al. (2001), pode-se deduzir que plantas cultivadas em solos argilosos apresentam melhor desenvolvimento agronômico em baixas dosagens de hidrogel, se comparado com os resultados obtidos pelos trabalhos realizados em solos arenosos.

Para o experimento realizado em 2012, verificou-se que a maior dose de hidrogel ( $24 \mathrm{~g}$ por vaso) acarretou redução na massa seca da parte aérea das plantas em comparação com a dose de 16 g por vaso, que pode ter ocorrido por excesso de umidade no solo, visto que nos solos que receberam essa dose de gel, a porosidade de aeração resultou em $0,09 \pm 0.13 \mathrm{~cm}^{3} \mathrm{~cm}^{-3}$ ao longo do cultivo da alface. NOBRE et al. (2009) avaliaram o crescimento e a produção de cultivares de alface 
em condições de solo saturado e constataram que elevado conteúdo de água no solo limita o acúmulo de fitomassa da parte aérea e das raízes da alface.

As plantas cultivadas em solo, na dose de $16 \mathrm{~g}$ de hidrogel por vaso, destacaram-se, principalmente na MFC e MSC (Figura 3), e ainda em NF, apresentando superioridade na produção. Para esta dose de gel, o conteúdo de água no solo permaneceu praticamente constante e em torno de $0,30 \mathrm{~cm}^{3} \mathrm{~cm}^{-3}$ (Figura $2 \mathrm{~b}$ ).

FOLTRAN \& TEIXEIRA (2004) avaliaram a incidência de Rhizoctonia sp. em plantas de alface cultivadas em solo arenoso com diferentes doses de hidrogel e observaram que, nos vasos com umidade na faixa de $0,3 \mathrm{~cm}^{3} \mathrm{~cm}^{-3}$, as plantas apresentaram maiores massas da parte aérea e de raízes.

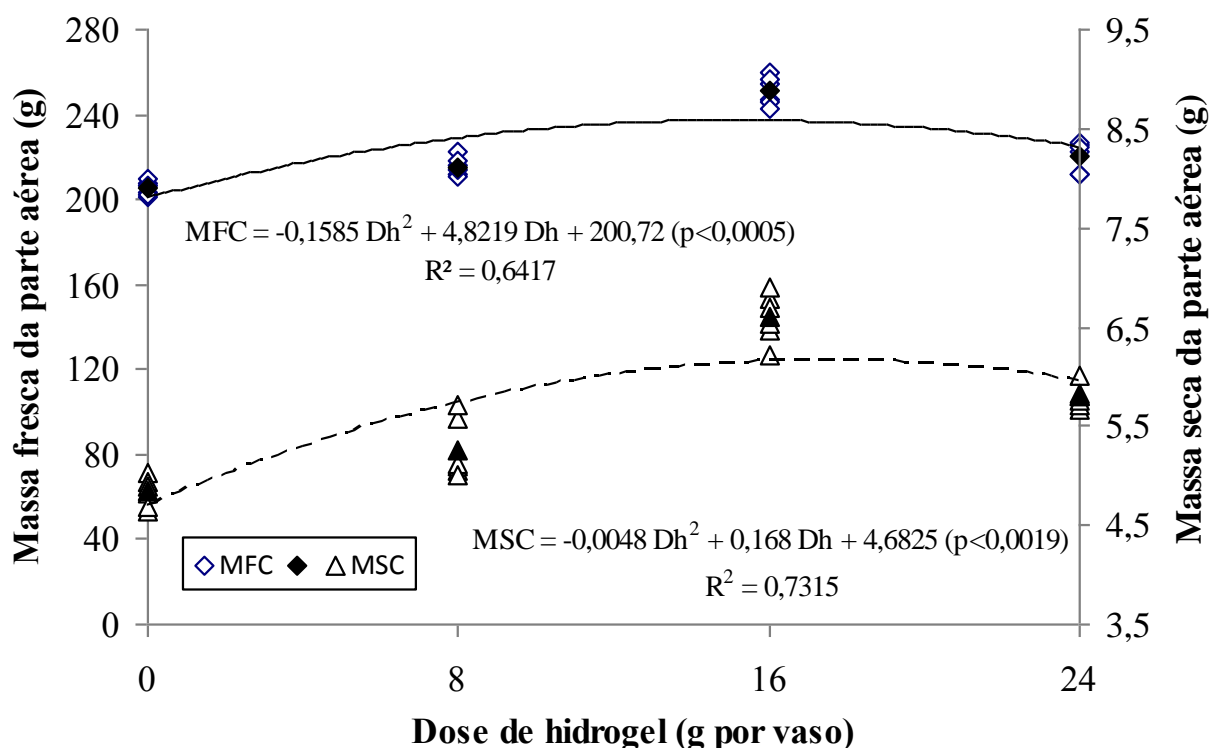

FIGURA 3. Análise de regressão para a MFC (a) e MSC (b) da alface em função de diferentes doses de hidrogel em solo arenoso. Regression analysis for shoot fresh (a) and dry mass (b) of lettuce under different doses of hydrogel in sandy soil.

A presença de hidrogel também proporcionou efeito significativo na massa fresca das raízes (MFR) (Figura 4), sendo obtidos maiores valores quanto maior a dosagem de polímero utilizada. A maior umidade do solo na presença do hidrogel (Figura $2 b$ ) pode ter proporcionado maior absorção de água pelas raízes e, consequentemente, maior MFR.

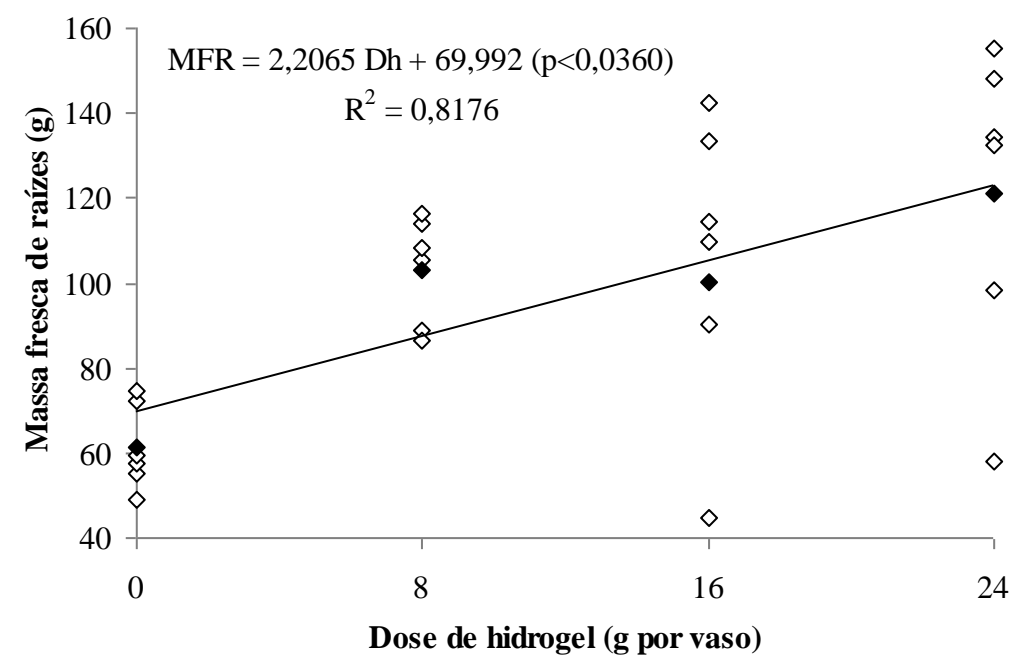

FIGURA 4. Regressão linear para a MFR da alface em função de diferentes doses de hidrogel em solo arenoso. Regression analysis for fresh root mass of lettuce under different doses of hydrogel in sandy soil. 
O uso de doses de hidrogel proporcionou EUA crescente até à dosagem de 16 g por vaso de 3 L (Figura 5). A partir daí a EUA decresce, pois, as plantas apresentaram menor acúmulo de MFC (Figura 3). Para essa dosagem, a EUA estimada pelo modelo quadrático é de $115,3 \mathrm{~kg} \mathrm{~m}^{-3}$. Além do fato de o cultivo de hortaliça em ambiente protegido permitir maior aproveitamento de água e nutrientes (BANDEIRA et al., 2011), o uso do hidrogel e o manejo automático da irrigação proporcionaram resultados expressivos quando comparados com o cultivo de alface em campo, sem o uso do hidrogel. Avaliando o desempenho da alface irrigada por gotejamento utilizando água de depósito na cidade de Campinas-SP, SANDRI et al. (2007) observaram EUA de $45,1 \mathrm{~kg} \mathrm{~m}^{-3}$. Adotando o mesmo manejo automático de irrigação, GOMES et al. (2014) obtiveram EUA de 32,5 $\mathrm{kg} \mathrm{m}^{-3}$ para a alface em sistema orgânico de produção e irrigada por gotejamento. Utilizando o manejo da irrigação pelo tanque Classe A, LIMA et al. (2009) encontraram EUA de $62,5 \mathrm{~kg} \mathrm{~m}^{-3}$ para alface irrigada por aspersão e utilizando cobertura de gliricídia.

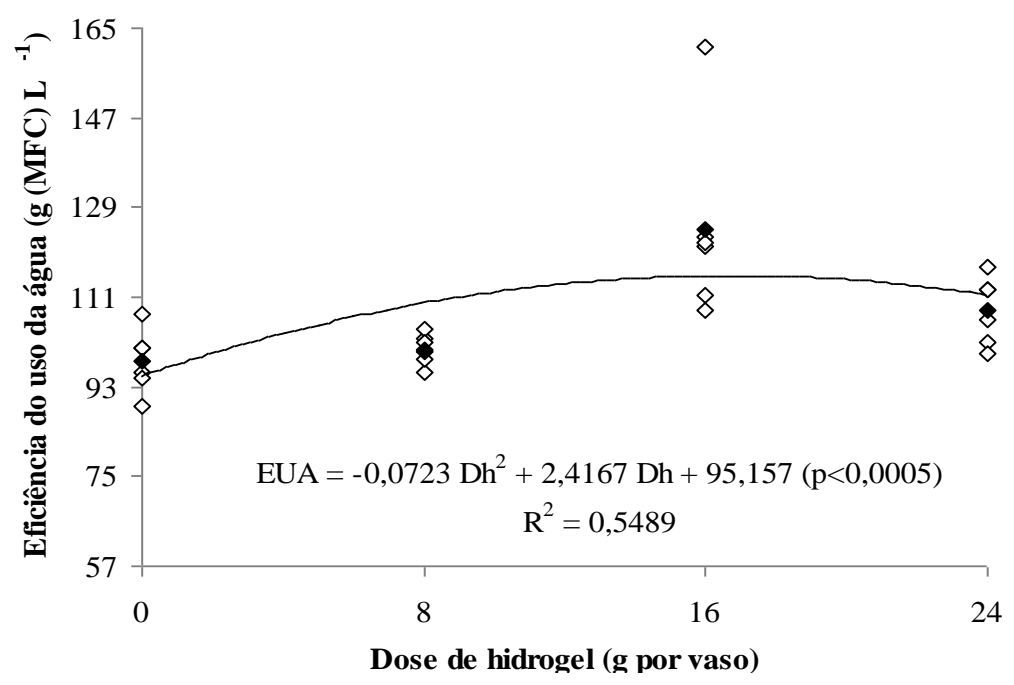

FIGURA 5. Análise de regressão para a EUA da alface em função de diferentes doses de hidrogel em solo arenoso. Regression analysis for lettuce water use efficiency under different doses of hydrogel in sandy soil.

\section{CONCLUSÕES}

O uso de hidrogel possibilitou maior eficiência do uso da água no cultivo protegido da alface. É recomendado adotar dosagens de hidrogel de até $16 \mathrm{~g}$ planta $^{-1}$ em solo arenoso para produzir alface lisa cv. Regina em ambiente protegido. A alface cultivada em solo argiloso apresentou melhor produção em baixas dosagens de hidrogel se comparada com a alface produzida em solo arenoso. $\mathrm{O}$ hidrogel não representou um impedimento para o monitoramento do conteúdo de água do solo por meio da TDR, devendo, no entanto, ser realizada calibração para cada dose aplicada.

\section{AGRADECIMENTOS}

Este trabalho foi viabilizado com recursos do CNPq (bolsa IC/Proc. 115076/2010-7), da FAPERJ (Programa CNE/Proc. E-26/102.325/2009) e da CAPES (Programa AUXPE-PNPD 02779/09).

\section{REFERÊNCIAS}

ABEDI-KOUPAI, J.; SOHRAB, F.; SWARBRICK, G. Evaluation of hydrogel application on soil water retention characteristics. Journal of Plant Nutrition, New York, v.31, n.2, p.317-331, 2008.

AKHTER, J.; MAHMOOD, K.; MALIK, K.A.; MARDAN, A.; AHMED, M.; IQBAL, M.M. Effects of hydrogel amendment on water storage of sandy loam and loam soils and seedlings growth of barley, wheat and chickpea. Plant, Soil and Environment, Prague, v.50, n.10, p.463469, 2004. 
ALBUQUERQUE FILHO, J.A.C.; LIMA, V.L.A.; MENEZES, D.; AZEVEDO, C.A.V.; NETO, J.D.; SILVA JÚNIOR, J.G. Características vegetativas do coentro submetido a doses do polímero hidroabsorvente e lâminas de irrigação. Revista Brasileira de Engenharia Agrícola e Ambiental, Campina Grande, v.13, n.6, p.671-679, 2009.

BAKASS, M.; MOKHLISSE, A.; LALLEMAN, T.M. Absorption and desorption of liquid water by a superabsorbent polymer: Effect of polymer in the drying of the soil and the quality of certain plants. Journal of Applied Polymer Science, New York, v.83, n.2, p.234-243, 2002.

BANDEIRA, G.R.L.; PINTO, H.C.S.; MAGALHÃES, P.S.; ARAGÃO, C.A.; QUEIROZ, S.O.P.; SOUZA, E.R.; SEIDO, S.L. Manejo de irrigação para cultivo de alface em ambiente protegido.

Horticultura Brasileira, Brasilia, v.29, p.237-241, 2011.

BATISTA, S.C.O.; CARVALHO, D.F.; ROCHA, H.S.; THANER DOS SANTOS, H.; MEDICI, L.O. Production of lettuce automatically watered with a low cost controller. Journal of Food, Agriculture \& Environment, Helsinki, v.11, n.2, p.485-489, 2013.

BERNARDI, A.C.C.; TAVARES, S.R.L.; SCHMITZ, A.A. Produção de meloeiro utilizando um polímero hidrofílico em diferentes frequências de irrigação em casa de vegetação. Irriga, Botucatu, v.10, n.1, p.82-87, 2005.

BEZERRA NETO, F.; GOES, S.B.; SÁ, J.R.; LINHARES, P.C.F.; GÓES, G.B.; MOREIRA, J.N.; Desempenho agronômico da alface em diferentes quantidades e tempos de decomposição de jitirana verde. Revista Brasileira de Ciências Agrárias, Recife, v.6, n.2, p.236-242, 2011.

CARVALHO, D.F.; OLIVEIRA NETO, D.H.; RIBEIRO, R.L.D.; GUERRA, J,G.M.; ROUWS, J.R.C. Manejo da irrigação associada a coberturas mortas vegetais no cultivo orgânico da beterraba. Engenharia Agrícola, Jaboticabal, v.31, n.2, p.269-277, 2011.

CARVALHO, D.F.; SILVA, D.G.; ROCHA, H.S.; ALMEIDA, W.S.; SOUSA. E.S.

Evapotranspiration and crop coefficient for potato in organic farm. Engenharia Agrícola, Jaboticabal, v. 33, p.201-211, 2013.

COELHO, J.B.M; BARROS, M.F.C.; CORREA, M.M; WANDERLEY, R.A; COELHO JÚNIOR, J.M.; FIGUEREDO, J.L.C. Efeito do polímero hidratassolo sobre propriedades físico-hídricas de três solos. Revista Brasileira de Ciências Agrárias, Recife, v.3, n.3, p.253-259, 2008.

EKEBAFE, L.O.; OGBEIFUN, D.E.; OKIEIMEN, F.E. Polymer applications in agriculture. Biokemistri, Nigeria, v.23, n.2, p.81-89, 2011.

EMBRAPA - Empresa Brasileira de Pesquisa Agropecuária. Manual de métodos de análise de solo / Centro Nacional de Pesquisa de Solos. 2. ed. Rio de Janeiro: EMBRAPA/CNPS, 2011. $212 p$.

FOLTRAN, B.N.; TEIXEIRA, E.S. Incidência de Rhizoctonia sp. em plantas de alface (Lactuca sativa L.) cultivadas em solo com polímero hidrorretentor. Revista Acadêmica: Ciências Agrárias e Ambientais, Curitiba, v.2, n.4, p.71-79, 2004.

GOMES, D.P.; CARVALHO, D.F.; ALMEIDA, W.S.; MEDICI, L.O.; GUERRA, J.G.M. Organic carrot-lettuce intercropping using mulch and different irrigation levels. International Journal of Food, Agriculture and Environment, Helsinki, v. 12, p.323-328, 2014.

HENDERSON, J.C.; DAVIES, F.T.; PEMBERTON, H.B. Landscape rose response to low moisture levels and a hydrophilic gel. Scientia Horticulturae, New York, v.46, p.129-135, 1991.

HENDERSON, J.C.; HENSLEY, D.L. Efficacy of a hydrophilic gel as a transplant aid. HortScience, Alexandria, v.21, n.4, p.991-992, 1986.

IDOBRO, H.J.; RODRÍGUEZ, A.M.; ORTÍZ, J.M.E. Comportamiento del hidrogel en suelos arenosos. Ingeniería de Recursos Naturales y del Ambiente, Cali, n.9, p.33-37, 2010. 
KAPS, M.; LAMBERSON, W.R. Biostatistics for animal science. Wallingford: CAB International, 2004. 459 p.

LEPSCH, I.F. Formação e conservação dos solos. São Paulo: Oficina de Textos, 2002.

LIMA JÚNIOR, J.A.; PEREIRA, G.M.; GEISENHOFF, L.O.; COSTA, G.G.; VILAS BOAS, R.C.; YURI, J.E. Efeito da irrigação sobre o rendimento produtivo da alface americana, em cultivo protegido. Revista Brasileira de Engenharia Agrícola e Ambiental, Campina Grande, v.14, n.8, p.797-803, 2010.

LIMA, L.M.L.; TEODORO, R.E.F.; FERNANDES, D.L.; CARVALHO, H.P.; MENDONÇA, F.C.; CARVALHO, J.O.M. Coffee seedling production under different irrigation levels and doses of a hydroabsorbent polymer. Bioscience Journal, Uberlândia, v.19, n.3, p. 27-30, 2003.

LIMA, M.E.; CARVALHO, D.F.; SOUZA, A.P.; GUERRA, J.G.M.; RIBEIRO, R.L.D.

Desempenho da alface em cultivo orgânico com e sem cobertura morta e diferentes lâminas d'água. Ciência e Agrotecnologia, Lavras, v.33, n.6, p.1503-1510, 2009.

MEDICI, L.O.; ROCHA, H.S.; CARVALHO, D.F.; PIMENTEL, C.; AZEVEDO, R.A. Automatic controller to water plants. Scientia Agricola, Piracicaba, v.67, n.6, p.727-730. 2010.

MORAES, O.; BOTREL, T.A.; DIAS, C.T.S. Efeito do uso de polímero hidrorretentor no solo sobre intervalo de irrigação na cultura da alface (Lactuca sativa L.). Engenharia Rural, Piracicaba, v.12, n.1, p.73-80, 2001.

NOBRE, R.G.; FERNANDES, P.D.; GHEYI, H.R.; BRITO, M.E.B.; SILVA, L.A. Crescimento da alface sob saturação temporal do solo. Revista Brasileira de Engenharia Agrícola e Ambiental, Campina Grande, v.13, p.890-898, 2009. Suplemento.

PEREIRA, S.; FILHO, D.O.; MANTOVANI, E.C.; RAMOS, M.M.; MARTINS, J.H.

Reflectometria no domínio do tempo na determinação do conteúdo de água no solo. Revista

Brasileira de Engenharia Agrícola e Ambiental, Campina Grande, v.10, n.2, p. 306-314, 2006.

PREVEDELLO, C.L.; LOYOLA, J.M.T. Efeito de polímeros hidrorretentores na infiltração da água no solo. Scientia Agraria, Curitiba, v.8, n.3, p.313-317, 2007.

REHMAN, A.; AHMAD, R.; SAFDAR, M. Effect of hydrogel on the performance of aerobic rice sown under different techniques. Plant, Soil and Environment, Praga, v.57, n.7, p.321-325, 2011.

ROMERO, R; MURIEL, J.L.; GARCÍA, I.; MUÑOZ DE LA PEÑA, D. Research automatic irrigation control: The art and recent results. Agricultural Water Management, Amsterdam, v.114, p.59-66, 2012.

SANDRI, D.; MATSURA, E. E.; TESTEZLAF, R. Desenvolvimento da alface Elisa em diferentes sistemas de irrigação com água residuária. Revista Brasileira de Engenharia Agrícola e Ambiental, Campina Grande, v.11, n.1, p. 17-29, 2007.

SALA, F.C.; COSTA, C.P. Retrospectiva e tendência da alfacicultura brasileira. Horticultura Brasileira, Brasília, v.30, n.2, p.187-194, 2012.

SILVA, L.J.B.; CAVALCANTE, A.S.S.; ARAÚJO NETO, S.E. Production of rocket (Eruca sativa) seedlings with substrates composed of organic waste. Ciência e Agrotecnologia, Lavras, v.33, n.5, p.1301-1306, 2009.

SOUZA, C.F.; FOLEGATTI, M.V. Spatial and temporal characterization of water and solute distribution patterns. Scientia Agricola, Piracicaba, v.67, p.09-15, 2011.

WILLINGHAM, J.E.; COFFEY, D.L. Influence of hydrophilic polymer amended soil in growth of tomato. HortScience, Alexandria, v.16, n.3, p.289-289, 1981.

ZONTA, J.H.; BRAUN, H.; REIS, E.F.; PAULUCIO, D.; ZONTA, J.B.; Influência de diferentes turnos de rega e doses de hidroabsorvente no desenvolvimento inicial da cultura do café conillon (Coffea canephora Pierre). IDESIA, Santiago, v.27, n.3, p.29-34, 2009. 